\title{
The development and effect of an education program on hand hygiene and use of personal protective equipment: a randomized controlled study
}

\author{
Eun-gyeong $\mathrm{Kim}^{1}$, Ihn Sook Jeong ${ }^{2}$ \\ ${ }^{1}$ Tansen School of Health Science, Tansen, Palpa, Nepal \\ ${ }^{2}$ College of Nursing, Pusan National University, Yangsan, Republic of Korea \\ doi: 10.3396/ijic.v15i4.014.19
}

\begin{abstract}
This study aimed to evaluate the effect of an education program on the accuracy of performance of hand hygiene $(\mathrm{HH})$ and the use of personal protective equipment (PPE) over time. This randomized controlled pretest-posttest study was performed with 34 experimental and 34 control group participants in the Western Development Region of Nepal. The intervention was a three hours education program on how to perform HH and use PPE, using multifaceted methods such as watching a movie, demonstration, practice, and peer feedback. The accuracy of $\mathrm{HH}$ and PPE use was measured three times with an observation checklist and was analyzed with a repeatedmeasures ANOVA. The experimental group showed higher increase in accuracy of $\mathrm{HH}(\mathrm{F}=40.78, \mathrm{p}<0.001)$, putting on PPE ( $F=112.75, p<0.001)$, and taking off PPE $(F=34.72, p<0.001)$ than the control group. As the education program had positive effects on the accuracy of $\mathrm{HH}$ and PPE use among nurses in Nepal, we suggest that the program be widely applied to healthcare workers in Nepal. Considering the decrease in the effect of the program on proper $\mathrm{HH}$ and PPE over time, it is recommended to provide re-education on $\mathrm{HH}$ and PPE at least three months and one month later, respectively.
\end{abstract}

Keywords: Hand hygiene, personal protective equipment, education, Nepal

\section{Corresponding Author}

Jeong, Ihn Sook

College of Nursing, Pusan National University

49 BusanDaehak-ro Mulgeum-eup Yangsan-si, 626-870, Gyeongnam, Republic of Korea

E-mail: jeongis@pusan.ac.kr 


\section{Introduction}

Isolation precaution (IP) is a basic and well-known efficient method for protecting patients from health care associated infections (HAls). ${ }^{1}$ Hand hygiene $(\mathrm{HH})$, one component of IP, is the most convenient yet effective method to reduce HAls by blocking the microbial transmission pathway. ${ }^{2}$ Increasing $\mathrm{HH}$ compliance from $48 \%$ to $66 \%$ resulted in reduction of HAls from $16.9 \%$ to $9.9 \% .{ }^{3}$ However, nurses spend less time on $\mathrm{HH}$ than recommended, ${ }^{4}$ and nurses usually do not follow the recommended six steps of $\mathrm{HH} .{ }^{5}$ The use of personal protective equipment (PPE) is another effective way to prevent the transmission of HAls. ${ }^{6,7}$ It is crucial to know how to use PPE properly because of high chances of self-contamination and subsequent infection while putting on and taking off the equipment. ${ }^{6.8}$ However, only $55 \%$ and $53.1 \%$ of nurses followed the proper process for putting on and taking off their PPE, respectively. ${ }^{9}$

Despite the high risk of HAls in Nepal, ${ }^{10}$ Nepalese nurses showed a considerably low level of knowledge on control of HAls and reported little chance for education on the control of HAls. ${ }^{11}$ Considering that education always has significant effects on improving knowledge and infection control, ${ }^{12}$ it is urgently required for Nepalese nurses to receive education on the control of HAls. Therefore, this study aimed to develop an education program on $\mathrm{HH}$ and use of PPE based on assessment of the educational need of Nepalese nurses and to evaluate the effects on the accuracy of $\mathrm{HH}$ and PPE over time.

\section{Methods}

\section{Study design}

This study adopted a randomized controlled and non-synchronized pretest-posttest design. The intervention was a three-hour education program, and the accuracy of $\mathrm{HH}$ and PPE use was measured three times: one day, one month, and three months after the intervention.

\section{Study participants}

Study participants were Nepalese nurses from L University Hospital in the Western Developing Region of Nepal who were able to read, write, and understand English and had voluntarily submitted written consent with understanding of the purpose of the study. The required number of participants was 62 for the repeated-measures ANOVA using 0.05 for significance level, 0.15 for effect size (f), 0.80 for statistical power (1- $\beta$ ), and four repeated measurements. Considering a $10 \%$ dropout rate, the final required sample size was 68 with 34 participants in each of experimental and control groups.

Randomization was performed by drawing from an envelope containing papers with 1 (control group) or 2 (experimental group) written on them. Once either group reached 34 participants, the remaining participants were sent to the other group to maintain a 1:1 ratio. There were no dropouts in the study, and all participants were included in the analysis.

\section{Study instruments}

Data were collected using a questionnaire for general characteristics and observational checklists for accuracy of $\mathrm{HH}$ and PPE use. General characteristics included age, gender, education level, working department, and work experience. Observational checklists were developed by the researchers based on the World Health Organization's Guidelines on Hand Hygiene in Health Care and the US Centers for Disease Control and Prevention's Guidance on Personal Protective Equipment. ${ }^{13,14}$ The checklist included nine questions on $\mathrm{HH}$, seven questions on putting on PPE, and nine questions on taking off PPE. For each question, one point was given if correctly carried out ("Yes"), and zero points were given if not ("No"). A higher score indicated higher accuracy of $\mathrm{HH}$ or putting on or taking off PPE.

\section{Intervention}

Prior to developing the education program, in-depth focus group interviews with 18 nurses (six nurses in three groups) were done to identify preferred contents, educational method, media, time, and attraction to activate learning motivation. Based on the interviews, an education program draft was composed as follows: history and importance of $\mathrm{HH}$, transmission of pathogens by hands, five moments for $\mathrm{HH}, \mathrm{HH}$ practice, definition and selection of PPE, and practice of putting on and taking off PPE. The education methods were lectures using PowerPoint slides and a video clip regarding transmission of 
infections through hands, watching a drama, and practice and peer feedback. The research team developed nine scenarios for dramas about a conflict regarding whether or not to use $\mathrm{HH}$ or PPE with eight minutes of running time. The total education time was set at three hours: one and a half hours for $\mathrm{HH}$ (including practice) and one and a half hours for PPE (including practice). The draft of the developed education program was reviewed by two Nepali professors of nursing and two Nepali nurses to consider Nepalese culture and local context.

\section{Study procedure}

After getting IRB approval from the University Institutional Review Board, the pre-test was done by two research assistants educated on how to collect data and showed good intra-class correlation coefficients: 0.98 in total, 0.94 in $\mathrm{HH}, 0.96$ in putting on PPE, and 0.95 in taking off PPE. The participants were asked to complete the informed consent form and were given a structured questionnaire regarding general characteristics, which was then collected. Thereafter, the two research assistants were split into different rooms and measured the accuracy of $\mathrm{HH}$ and PPE use in sequence with observation checklists. Participants were asked to put on the PPE, remove it, and then demonstrate $\mathrm{HH}$. To restrict meeting with other participants yet to be tested, the participants were asked to exit through a different door after the pre-test.

The education program was conducted for the experimental group by one of the researchers while the control group had no specific intervention; they were provided with the same education program after completion of the study. A post-test was performed one day, one month, and three months from the end of the education program for the experimental group or pre-test for the control group in the same manner as the pre-test by the two research assistants.

\section{Statistical analysis}

Data were analyzed using SPSS software (IBM Corp. Released 2015. IBM SPSS Statistics for Windows, Version 23.0.Armonk, NY: IBM Corp.) with significance level $(a)<0.05$. Homogeneity between groups was analyzed using $\mathrm{X}^{2}$-test and $\mathrm{t}$-test. The changes in accuracy of $\mathrm{HH}$ and PPE use between groups were analyzed with a repeated-measures ANOVA.

\section{Results}

\section{Homogeneity of participants}

For the experimental group, the mean age was 21.61 years, and the mean work experience was 20 months; $52.9 \%$ of the nurses worked in the department of surgery. For the control group, the mean age was 22.44 years, and the mean work experience was 23 months. Accuracy of $\mathrm{HH}$, putting on PPE, and taking off PPE was $4.76,1.85$, and 4.38 points, respectively, for the experimental group and 5.03, 1.97, and 4.77 points, respectively, for the control group. There were no significant differences in general characteristics or accuracy of $\mathrm{HH}$, putting on PPE, and taking off PPE between the groups.

\section{Accuracy of $\mathrm{HH}$}

Accuracy of $\mathrm{HH}$ for the experimental group showed a big increase from 4.76 out of 9 points before intervention to 7.53 points three months after intervention while there were barely any changes (from 5.03 points before intervention to 5.00 points three months after intervention) for the control group. Accuracy of $\mathrm{HH}$ before and after intervention between groups was significantly different $(F=40.78$, $\mathrm{p}<0.001$ ) (Table l).

\section{Accuracy of putting on PPE}

Accuracy of putting on PPE was 1.09 out of 7 points before the intervention and 5.38 points three months after the intervention for the experimental group while it was 1.29 points before intervention and 1.68 points three months after intervention for the control group. Accuracy of putting on PPE before and after intervention was significantly different between the groups ( $F=112.75, p<0.001)$ (Table II).

\section{Accuracy of taking off PPE}

Accuracy of taking off PPE was 3.56 out of 9 points before intervention and 6.91 points three months after intervention for the experimental group while it was 3.97 points before intervention and 3.53 points three months after intervention for the control group. Accuracy of taking off PPE before and after intervention was significantly different between the groups ( $F=34.72, p<0.001$ ) (Table III). 
Table I. Changes in accuracy of hand hygiene over time $(\mathrm{N}=68)$

\begin{tabular}{|c|c|c|c|c|c|}
\hline \multirow[t]{2}{*}{ Take observed } & & Pretest & $\begin{array}{l}\text { After } \\
1 \text { day }\end{array}$ & $\begin{array}{r}\text { After } \\
1 \text { month }\end{array}$ & $\begin{array}{r}\text { After } \\
3 \text { months }\end{array}$ \\
\hline & & $\mathrm{n}(\%)$ & $\mathrm{n}(\%)$ & $\mathrm{n}(\%)$ & $n(\%)$ \\
\hline \multirow{2}{*}{$\begin{array}{l}\text { Apply the product to cupped hand, } \\
\text { covering all surfaces. }\end{array}$} & Exp. & $0(0.0)$ & 31 (91.2) & $34(100.0)$ & $34(100.0)$ \\
\hline & Cont. & $0(0.0)$ & $1(2.9)$ & $3(8.8)$ & $0(0.0)$ \\
\hline \multirow{2}{*}{ Rub hands palm to palm. } & Exp. & $21(61.8)$ & $34(100)$ & $34(100.0)$ & $34(100.0)$ \\
\hline & Cont. & $21(61.8)$ & $21(61.8)$ & $22(64.7)$ & $21(61.8)$ \\
\hline \multirow{2}{*}{$\begin{array}{l}\text { Rub right palm over left dorsum with } \\
\text { interlaced fingers and vice versa. }\end{array}$} & Exp. & $29(85.3)$ & $30(88.2)$ & $34(100.0)$ & $31(91.2)$ \\
\hline & Cont. & $33(97.1)$ & $30(88.2)$ & $25(73.5)$ & $27(79.4)$ \\
\hline \multirow{2}{*}{$\begin{array}{l}\text { Rub palm to palm with interlaced } \\
\text { fingers. }\end{array}$} & Exp. & $10(29.4)$ & $33(97.1)$ & $34(100.0)$ & $20(58.8)$ \\
\hline & Cont. & $12(65.3)$ & $10(29.4)$ & $7(20.6)$ & $15(44.1)$ \\
\hline \multirow{2}{*}{$\begin{array}{l}\text { Rotational rubbing of left thumb } \\
\text { clasped in right palm and vice versa. }\end{array}$} & Exp. & $23(67.6)$ & $30(88.2)$ & $34(100.0)$ & 30 (88.2) \\
\hline & Cont. & $27(79.4)$ & $24(70.6)$ & $22(64.7)$ & $24(70.6)$ \\
\hline \multirow{2}{*}{$\begin{array}{l}\text { Rub backs of fingers to opposing } \\
\text { palms with fingers interlocked. }\end{array}$} & Exp. & $28(82.4)$ & $34(100)$ & $34(100.0)$ & 31 (91.2) \\
\hline & Cont. & $25(73.5)$ & $25(73.5)$ & $27(79.4)$ & $24(70.6)$ \\
\hline \multirow{2}{*}{$\begin{array}{l}\text { Rotational rubbing, backwards and } \\
\text { forwards with clasped fingers of right } \\
\text { hand in left palm and vice versa. }\end{array}$} & Exp. & $27(79.4)$ & $33(97.1)$ & $34(100.0)$ & 30 (88.2) \\
\hline & Cont. & $26(76.5)$ & $28(82.4)$ & $27(79.4)$ & $27(79.4)$ \\
\hline \multirow{2}{*}{ Once dry, hand hygiene is complete. } & Exp. & $13(38.2)$ & $24(70.6)$ & $30(88.2)$ & $26(76.5)$ \\
\hline & Cont. & $11(32.4)$ & $6(17.6)$ & $14(41.2)$ & $15(44.1)$ \\
\hline \multirow{3}{*}{$\begin{array}{l}\text { Performing hand-rub for } 20-30 \\
\text { seconds. }\end{array}$} & Exp. & $11(32.4)$ & $26(76.5)$ & $27(79.4)$ & $20(58.8)$ \\
\hline & Cont. & $16(47.1)$ & $16(47.1)$ & $12(35.3)$ & $17(50.0)$ \\
\hline & & mean $\pm S D$ & mean $\pm S D$ & mean $\pm S D$ & mean $\pm S D$ \\
\hline \multirow[t]{5}{*}{ Total } & Exp. & $4.76 \pm 1.65$ & $8.09 \pm 1.11$ & $8.68 \pm 0.64$ & $7.53 \pm 1.44$ \\
\hline & Cont. & $5.03 \pm 1.47$ & $4.74 \pm 1.54$ & $4.68 \pm 1.79$ & $5.00 \pm 1.33$ \\
\hline & & \multicolumn{4}{|c|}{ Group $(F=110.61, p<0.001)$} \\
\hline & & \multicolumn{4}{|c|}{ Time $(F=29.25, p<0.001)$} \\
\hline & & \multicolumn{4}{|c|}{ Group*Time $(F=40.78, p<0.001)$} \\
\hline
\end{tabular}

$\mathrm{PPE}=$ personal protective equipment, $\mathrm{Exp} .=$ experimental group, Cont. $=$ control group 
Table II. Changes in accuracy of donning PPE over time ( $\mathrm{N}=68)$

\begin{tabular}{|c|c|c|c|c|c|}
\hline Donning PPE & & \multirow{2}{*}{$\begin{array}{r}\text { Pretest } \\
\mathrm{n}(\%)\end{array}$} & \multirow{2}{*}{$\begin{array}{l}\text { After } \\
1 \text { day } \\
\mathrm{n}(\%) \\
\end{array}$} & \multirow{2}{*}{$\begin{array}{r}\text { After } \\
1 \text { month } \\
\mathrm{n}(\%) \\
\end{array}$} & \multirow{2}{*}{$\begin{array}{r}\text { After } \\
3 \text { months } \\
\mathrm{n}(\%) \\
\end{array}$} \\
\hline & & & & & \\
\hline \multirow{2}{*}{$\begin{array}{l}\text { Perform hand hygiene before } \\
\text { donning PPE. }\end{array}$} & Exp. & $24(70.6)$ & $33(97.1)$ & $34(100.0)$ & $34(100.0)$ \\
\hline & Cont. & $28(82.4)$ & $27(79.4)$ & $31(91.2)$ & $30(88.2)$ \\
\hline \multirow{2}{*}{$\begin{array}{l}\text { Tie the gown at both the neck and } \\
\text { waist. }\end{array}$} & Exp. & $1(2.9)$ & $32(94.1)$ & $27(79.4)$ & $29(85.3)$ \\
\hline & Cont. & $1(2.9)$ & $0(0.0)$ & $0(0.0)$ & $2(5.9)$ \\
\hline \multirow{2}{*}{$\begin{array}{l}\text { Place mask straps properly (at the } \\
\text { middle of head and neck). }\end{array}$} & Exp. & $0(0.0)$ & $31(91.2)$ & $28(82.4)$ & $25(73.5)$ \\
\hline & Cont. & $3(8.8)$ & $4(11.8)$ & $7(20.6)$ & $6(47.6)$ \\
\hline \multirow{2}{*}{$\begin{array}{l}\text { Properly seal the mask to the face. } \\
\text { (fit flexible band to nose bridge) }\end{array}$} & Exp. & $0(0.0)$ & $30(88.2)$ & $26(76.5)$ & $21(61.8)$ \\
\hline & Cont. & $0(0.0)$ & $0(0.0)$ & $0(0.0)$ & $0(0.0)$ \\
\hline \multirow{2}{*}{ Conduct a seal check. } & Exp. & $0(0.0)$ & $26(76.5)$ & $25(73.5)$ & $17(50.0)$ \\
\hline & Cont. & $0(0.0)$ & $0(0.0)$ & $0(0.0)$ & $0(0.0)$ \\
\hline \multirow{2}{*}{ Glove cuff covers gown cuff. } & Exp. & $10(29.4)$ & $30(88.2)$ & 31 (91.2) & $26(76.5)$ \\
\hline & Cont. & $9(26.5)$ & $16(47.1)$ & $15(44.1)$ & $18(52.9)$ \\
\hline \multirow{3}{*}{$\begin{array}{l}\text { Put on PPE in the CDC- } \\
\text { recommended sequence (Gown- } \\
\text { Mask-Gloves) }\end{array}$} & Exp. & $2(5.9)$ & 31 (91.2) & $34(100.0)$ & 31 (91.2) \\
\hline & Cont. & $3(8.8)$ & $4(11.8)$ & $1(2.9)$ & $1(2.9)$ \\
\hline & & mean $\pm S D$ & mean $\pm S D$ & mean $\pm S D$ & mean $\pm S D$ \\
\hline \multirow[t]{5}{*}{ Total } & Exp. & $1.09 \pm 0.62$ & $6.26 \pm 0.93$ & $6.03 \pm 1.19$ & $5.38 \pm 1.56$ \\
\hline & Cont. & $1.29 \pm 0.72$ & $1.50 \pm 0.83$ & $1.59 \pm 0.78$ & $1.68 \pm 0.98$ \\
\hline & & \multicolumn{4}{|c|}{ Group $(F=607.84, p<0.001)$} \\
\hline & & \multicolumn{4}{|c|}{ Time $(F=166.86, p<0.001)$} \\
\hline & & \multicolumn{4}{|c|}{ Group*Time $(F=112.75, p<0.001)$} \\
\hline
\end{tabular}

$\mathrm{PPE}=$ personal protective equipment, $\mathrm{Exp} .=$ experimental group, Cont. $=$ control group

\section{Discussion}

Nepalese nurses who completed the education program had increased accuracy for both $\mathrm{HH}$ and PPE use compared to the nurses without the education, indicating that the education program had positive effects on improving accuracy. As there was barely any education on $\mathrm{HH}$ or PPE use in the regular nursing program of Nepal, we performed an analysis of education needs and learning motivation through in-depth interviews of the nurses prior to developing the education program. It seemed that these analyses significantly contributed to the design of the program in consideration of the participants' level or cultural characteristics and also stimulated their motivation to learn. As adult healthcare workers are often selfmotivated to learn practical knowledge, and their learning is usually more effective, it is crucial to induce their learning motivation. ${ }^{15}$ Based on an ARCS model, ${ }^{16}$ (Attention, Relevance, Confidence and Satisfaction (ARCS) Model of Motivation) learning objectives were presented, and scenarios involving possible conflicts in the work situation were made into dramas to foster both a sense of closeness and relevance of learning. Moreover, conditions for success were outlined prior 
Table III. Changes in accuracy of doffing PPE over time ( $\mathrm{N}=68)$

\begin{tabular}{|c|c|c|c|c|c|}
\hline \multirow[t]{2}{*}{ Doffing PPE } & & Pretest & $\begin{array}{l}\text { After } \\
1 \text { day }\end{array}$ & $\begin{array}{r}\text { After } \\
1 \text { month } \\
\end{array}$ & $\begin{array}{r}\text { After } \\
3 \text { months } \\
\end{array}$ \\
\hline & & $\mathrm{n}(\%)$ & $\mathrm{n}(\%)$ & $\mathrm{n}(\%)$ & $\mathrm{n}(\%)$ \\
\hline \multirow{2}{*}{$\begin{array}{l}\text { Use proper glove-in-glove technique for } \\
\text { glove removal. }\end{array}$} & Exp. & $0(0.0)$ & $27(79.4)$ & $26(76.5)$ & $22(64.7)$ \\
\hline & Cont. & $1(2.9)$ & $1(2.9)$ & $0(0.0)$ & $0(0.0)$ \\
\hline \multirow{2}{*}{ Gloves were placed in the trash. } & Exp. & $29(85.3)$ & $31(91.2)$ & $30(88.2)$ & 30 (88.2) \\
\hline & Cont. & $32(94.1)$ & $27(79.4)$ & $24(70.6)$ & $20(58.8)$ \\
\hline \multirow{2}{*}{$\begin{array}{l}\text { Use proper technique for gown removal. } \\
\text { (Touch inside of Gown only, turn gown } \\
\text { inside out) }\end{array}$} & Exp. & $0(0.0)$ & $27(79.4)$ & $28(82.4)$ & $22(64.7)$ \\
\hline & Cont. & $0(0.0)$ & $2(5.9)$ & $0(0.0)$ & $1(2.9)$ \\
\hline \multirow{2}{*}{$\begin{array}{l}\text { Use the foot pedal, but instead touched } \\
\text { the hamper lid with bare hand. }\end{array}$} & Exp. & $26(76.5)$ & $33(97.1)$ & $31(91.2)$ & $29(85.3)$ \\
\hline & Cont. & $25(73.5)$ & $29(85.3)$ & $28(82.4)$ & $23(67.6)$ \\
\hline \multirow{2}{*}{$\begin{array}{l}\text { Place all or part of the gown into the } \\
\text { designated hamper. }\end{array}$} & Exp. & $22(64.7)$ & $34(100.0)$ & $27(79.4)$ & $25(73.5)$ \\
\hline & Cont. & $22(64.7)$ & $16(47.1)$ & $19(55.9)$ & $8(23.5)$ \\
\hline \multirow{2}{*}{$\begin{array}{l}\text { Use proper mask removal technique. (Grasp } \\
\text { bottom ties of elastics of the mask, then the } \\
\text { ones at the top, remove without touching the } \\
\text { front) }\end{array}$} & Exp. & $0(0.0)$ & $25(73.5)$ & $30(88.2)$ & $14(41.2)$ \\
\hline & Cont. & $1(2.9)$ & $2(5.9)$ & $0(0.0)$ & $0(0.0)$ \\
\hline \multirow{2}{*}{ Place the mask into the trash. } & Exp. & $23(67.6)$ & $34(100.0)$ & $32(94.1)$ & 31 (91.2) \\
\hline & Cont. & $29(85.3)$ & $26(76.5)$ & $18(52.9)$ & $18(52.9)$ \\
\hline \multirow{2}{*}{$\begin{array}{l}\text { Perform hand hygiene after removing all } \\
\text { PPE. }\end{array}$} & Exp. & $5(14.7)$ & $34(100.0)$ & $33(97.1)$ & 31 (91.2) \\
\hline & Cont. & $5(14.7)$ & $14(41.2)$ & $20(58.8)$ & $24(70.6)$ \\
\hline \multirow{3}{*}{$\begin{array}{l}\text { Doff equipment in the CDC recommended } \\
\text { sequence. (Gloves-Gown-Mask) }\end{array}$} & Exp. & $16(47.1)$ & $31(91.2)$ & $33(97.1)$ & 31 (91.2) \\
\hline & Cont. & $20(58.8)$ & $27(79.4)$ & $21(61.8)$ & $26(76.5)$ \\
\hline & & mean $\pm S D$ & mean $\pm S D$ & mean $\pm S D$ & mean $\pm S D$ \\
\hline \multirow[t]{5}{*}{ Total } & Exp. & $3.56 \pm 1.40$ & $8.12 \pm 1.04$ & $7.94 \pm 1.52$ & $6.91 \pm 1.78$ \\
\hline & Cont. & $3.97 \pm 1.31$ & $4.24 \pm 1.54$ & $3.82 \pm 1.70$ & $3.53 \pm 1.71$ \\
\hline & & \multicolumn{4}{|c|}{ Group ( $F=199.51, p<0.001)$} \\
\hline & & \multicolumn{4}{|c|}{ Time $(F=35.52, p<0.001)$} \\
\hline & & \multicolumn{4}{|c|}{ Group*Time $(F=34.72, p<0.001)$} \\
\hline
\end{tabular}

$\mathrm{PPE}=$ personal protective equipment, Exp.=experimental group, Cont.=control group

to performing the demonstration and practice for proper $\mathrm{HH}$ and PPE use, and then the participants were allowed to experience successful practices, which gave them further confidence. We believe that using different approaches (such as drama, practice, and group discussions) over traditional lectures likely induced interests for the participants.
The education program improved accuracy of "2030 seconds of $\mathrm{HH}$," but it still remained at a relatively low level (<60\%). In an observational study with 143 ICU healthcare workers, however, $74.4 \%$ of nurses and $82.0 \%$ of physicians spent less than 10 seconds washing their hands. ${ }^{5}$ In an analysis of 14 different studies, the average time spent for hand washing was 
4.7-24 seconds with seven studies below 10 seconds and seven studies between 10 and 24 seconds. ${ }^{17}$ These results showed that most healthcare workers spend less time washing their hands than has been recommended by the WHO. ${ }^{8}$ Considering these study results, instead of simply instructing nurses to spend 20-30 seconds for $\mathrm{HH}$, a Nepali song or refrain should be selected that is as long as the required time for $\mathrm{HH}$, and accompanying hand motions should be developed and taught to the nurses to help with proper application of $\mathrm{HH}$ and keeping the required time.

For putting on PPE, "tie the gown at both the neck and waist" and "put on PPE in CDC recommended sequence of gown-mask-gloves" showed considerably low levels of accuracy (5.9\%) before the education. This dramatically improved to $91.2 \%$ three months after the education, showing the largest educational effect. However, items for mask-wearing methods and conducting a seal check showed considerably low accuracy ( $0 \%$ ) before the education, and this remained at a relatively low levels of $50 \%$ three months after education. Beam et al. have shown that no healthcare workers knew about conducting a seal check before using masks. ${ }^{9}$ Since Nepal is one of the countries with the highest incidence of tuberculosis, ${ }^{18}$ they must recognize that proper use of masks for healthcare workers is crucial for prevention of cross-infection within medical institutions and provide continuous education on this issue.

For taking off PPE, "HH after PPE removal" showed dramatic improvement from $14.7 \%$ before the education to $91.2 \%$ three months after the education. However, "Use proper glove-in-glove technique for glove removal," "Use proper technique for gown removal," and "Use proper mask removal technique" had considerably low accuracy of $0 \%$ before the education, and this remained relatively low at $41.2 \%$ even three months after the education. Accuracy of taking off PPE was even lower than that of putting on PPE, and previous studies showed that only $56 \%$ of Canadian nurses working in hospitals removed their PPE in the order recommended by the CDC..$^{14,19}$ Since PPE bears risk of self-contamination during removal, 6,8 re-education should be provided to improve the accuracy of taking off PPE.
The effects of the education program slightly decreased at three months after the intervention for $\mathrm{HH}$ and at one month after the intervention for use of PPE. As shown in a previous study, ${ }^{20} \mathrm{HH}$ interventions remained effective up until certain time points and tended to decrease afterwards, indicating the need for re-intervention. For Nepalese nurses, it is recommended to provide re-education on $\mathrm{HH}$ and PPE at least within three months and one month from education, respectively.

This study developed and applied a systematic education program for Nepalese nurses and assessed its effectiveness for the first time. Furthermore, we minimized selection bias by randomizing participants. Non-synchronized design allowed prevention of intervention contamination to the control group, and the lack of dropouts in the study also minimized information bias. Particularly, the developed education program can bring actual improvement to accuracy of $\mathrm{HH}$ and PPE use, so it is expected that the program can be widely applied to nursing fields in Nepal.

However, there are a few limitations to consider when interpreting the results. First, as the study was done in a single hospital in the Western Developing Region of Nepal, generalisability is limited. Second, accuracy of $\mathrm{HH}$ and PPE use was measured four times, and testing effect could occur. However, both groups were measured four times, and the testing effect would have affected both groups and seems unlikely to have significant impact on the effectiveness of the education program. Third, $\mathrm{HH}$ and PPE use were socially desirable behaviours, and participants in the control group might have self-learning. Additional survey after the study showed that $56 \%$ and $82 \%$ of the participants in the control group self-learned about HH and PPE use, respectively. Since it was possible that such self-learning in the control group negatively affected the education program, it was expected that the actual effect of the education program on improving the accuracy of $\mathrm{HH}$ and PPE use should be greater than what was presented in the study.

In conclusion, the three-hour education program on $\mathrm{HH}$ and PPE use showed positive effects on improving 
the accuracy of $\mathrm{HH}$ and PPE use for Nepalese nurses. Therefore, we suggest that this education program should be applied to larger cohorts of healthcare workers-including nurses and physicians-working in medical institutions in Nepal. The effect of the education program decreased at three months after intervention for $\mathrm{HH}$ and at one month after for PPE use. Therefore, it is recommended to provide Nepalese nurses with re-education or other interventions to increase the accuracy after assessing the causes of decreasing the accuracy on $\mathrm{HH}$ and PPE on a regular basis.

\section{References}

1. Kanouff AJ, DeHaven KD, Kaplan PD. Prevention of nosocomial infections in the intensive care unit. Crit Care Nurs Q 2008; 31(4): 302-308. https://doi.org/10.1097/01. CNQ.0000336815.81676.88

2. World Health Organisation. WHO guidelines on hand hygiene in health care. World Health Organisation, Geneva. 2009. Available from: http://www.who.int/gpsc/5may/ tools/9789241597906/en/. (Accessed 5 March 2018)

3. Pittet D, Hugonnet $S$, Harbarth $S$, et al. Effectiveness of a hospital-wide programme to improve compliance with hand hygiene. Lancet 2000; 356(9238): 1307-1312. https://doi. org/10.1016/S0140-6736(00)02814-2

4. Rao MH, Arain GM, Khan MI, et al. Assessment of knowledge, attitude and practices pattern of hand washing in some major public sector hospitals of Pakistan (A Multi-Center Study). Pakistan J Med Res 2012; 51(3): 76A.

5. Lee MH, Kang HS. A comparative study on profession-specific handwashing practices of ICU health care providers. J Korean Acad Fundam Nurs 2007; 14(3): 297-305.

6. Siegel JD, Rhinehart E, Jackson M, Chiarello L, Health Care Infection Control Practices Advisory Committee. 2007 Guideline for isolation precautions: preventing transmission of infectious agents in health care settings. Am J Infect Control 2007; 35(Suppl 2): 65-164. https://doi.org/10.1016/j. ajic.2007.10.007

7. Valdez AM. Are you covered? Safe practices for the use of personal protective equipment. J Emerg Nurs 2015; 41(2): 154-157. https://doi.org/10.1016/j.jen.2014.11.011

8. Casanova L, Alfano-Sobsey E, Rutala WA, Weber DJ, Sobsey M. Virus transfer from personal protective equipment to healthcare employees' skin and clothing. Emerg Infect Dis 2008; 14(8): 1291-1293. https://doi.org/10.3201/ eid1408.080085

9. Beam EL, Gibbs SG, Boulter KC, Beckerdite ME, Smith PW. A method for evaluating health care workers' personal protective equipment technique. Am J Infect Control 2011; 39(5): 415-420. https://doi.org/10.1016/j.ajic.2010.07.009
10. Shrestha S, Shrestha R, Shrestha B, Dongol A. Incidence and risk factors of surgical site infection following cesarean section at Dhulikhel Hospital. Kathmandu Univ Med J 2014; 12(46): 113-116. https://doi.org/10.3126/kumj.v12i2.13656

11. Kim EG, Jeong IS, Thanju S. Knowledge, attitude, and compliance of healthcare-associated infection control among nurses in the western development region, Nepal. Korean J Nosocomial Infect Control 2016; 21(1): 9-17. https://doi. org/10.14192/kjnic.2016.21.1.9

12. Shrestha I. Impact of educational intervention on knowledge and practice of universal precautions among nurses. J Patan Acad Health Sci 2014; 1(1): 57-60. https://doi.org/10.3126/ jpahs.v1i1.13022

13. Center for Disease Control and Prevention. Guidance for the use and selection of personal protective equipment (PPE) in healthcare settings. 2004. Available from: http://www.cdc. gov/hai/pdfs/ppe/ppeslides6-29-04.pdf. (Accessed 5 March 2018)

14. Center for Disease Control and Prevention. Guideline for isolation precautions: Preventing transmission of infectious agents in healthcare settings. 2007. Available from: http:// www.cdc.gov/hicpac/2007IP/2007/solationPrecautions. $\mathrm{html}$. (Accessed 5 March 2018)

15. Sanchez LM, Cooknell LE. The Power of 3: Using adult learning principles to facilitate patient education. Nursing 2017; 47(2): 17-19. https://doi.org/10.1097/01. NURSE.0000511819.18774.85

16. Keller JM. Motivation and instructional design: a theoretical perspective. J Instruct Dev 1979; 2(4): 26-34. https://doi. org/10.1007/BF02904345

17. Boyce JM, Pittet D, Healthcare Infection Control Practices Advisory Committee; HICPAC/SHEA/APIC/IDSA Hand Hygiene Task Force. Guideline for Hand Hygiene in HealthCare Settings. Recommendations of the Healthcare Infection Control Practices Advisory Committee and the HIPAC/SHEA/ APIC/IDSA Hand Hygiene Task Force. Am J Infect Control 2002; 30(8): S1-S46. https://doi.org/10.1086/503164

18. Ministry of Health and Population. Nepal National Tuberculosis Programme Annual Report 2014. Available from http://www.nepalntp.gov.np/theme/images/uploads/NTP Annual_Report_2070-71_final.pdf. (Accessed 5 March 2018)

19. Mitchell R, Roth V, Gravel D, et al. Are health care workers protected? An observational study of selection and removal of personal protective equipment in Canadian acute care hospitals. Am J Infect Control 2013; 41(3): 240-244. https:// doi.org/10.1016/j.ajic.2012.04.332

20. Pong S, Holliday P, Fernie G. Effect of electronic real-time prompting on hand hygiene behaviors in health care workers. Am J Infect Control 2018; 46(7): 768-774. doi: 10.1016/j. ajic.2017.12.018. https://doi.org/10.1016/j.ajic.2017.12.018 